single-issue interest groups, and the professionalization of campaign staffs. Speakers and participants will also explore the changing role of minorities, particularly African Americans, in North Carolina politics.

\section{The New Majority}

Xavier University

Cincinnati, OH 45207

Director: Dr. Neil Heighberger,

(513) 745-3601

Dates: June 14-25, 1993

The Xavier seminar will examine the potential emergence of a new majority in American politics from two perspectives: first, the efforts of the new administration to fashion a new electoral, as well as legislative, majority in support of its agenda; and, second, the demographic trends that are literally changing the face of America and the definition of "majority." In particular, the course will focus on political and educational issues related to the largest minorities in the Cincinnati area: African Americans and Appalachians.

Building on the Momentum

Rhode Island College

Providence, RI 02908

Director: Dr. Victor Profughi, (401) 456-8056

Dates: June 21-July 2, 1993

While the 1992 election sparked increased interest and participation in the political process, will there be a lasting impact? Was the surge in citizen involvement a temporary phenomenon or the beginning of a new era? How can minorities, particularly immigrants, be encouraged to become active, informed citizens? Participants in the Rhode Island seminar will explore these and other questions through dialogue with some of the key actors in politics and government at the local, state, and national levels.

\section{Governmental Transitions:}

The Changing of the Guard

Tennessee State University

Nashville, TN 37209-1561

Director: Dr. Bruce Rogers, (615) 320-3015

Dates: June 14-25, 1993

The focus of this year's Tennessee seminar will be the transition between political campaigns and operational governments. How do campaign teams reorganize to form a new government? What conflicts arise in the shift from purely political activities to the more regularized activities of managing a government? Members of the Clinton-Gore transition team, and their counterparts at the local and state levels, will serve as guest faculty and provide an intimate look at the changing of the guard in American politics.
American Politics: A Study in Cultural and Political Diversity Southern University

Baton Rouge, LA 70813

Director: Dr. Jewel Prestage

Assistant Director: Dr. James Llorens, (504) $771-3210$

Dates: July 6-17, 1993

Now in its third year, the Southern University seminar will examine American historical and political development with special emphasis on the distinctive political cultue of Louisiana. Participants will review recent research on the political socialization and cognitive learning styles of minority children, as well as materials and methods to help them meet the challenge of classroom diversity.

Contemporary Government and Politics in Connecticut

Institute of Public Service

University of Connecticut

Storrs, CT 06269-4014

(203) 486-2828

Director: Dr. Edward C. Sembor

Dates: August 2-13, 1993

This new seminar, to be conducted on the West Hartford campus, will give teachers a better understanding of the American political system, with special emphasis on state and local government in Connecticut, citizenship education, and current urban public policy issues. Participants will receive assistance in applying new knowledge, methods, and materials in the classroom and will return for a one-day follow-up session during the 1993-94 school year.

\title{
Bringing Law to Bear on International Relations Theory Courses*
}

\author{
Nicholas G. Onuf, The American University \\ James Larry Taulbee, Emory University
}

As an area of serious study, international law has all but disappeared from the contemporary curricula of political science and international relations (IR) in the United States. Basic courses in international relations at the undergraduate level give fleeting attention to international law, reflecting both the attitudes of instructors and the desultory and antiquated treatment in most basic textbooks (Taulbee 1988). Many undergraduate curricula still sport an upper division course, for which pre- law majors serve as a reliable constituency, but upon close examination these courses often prove to be anomalies, rather than a core part of an integrated plan of study. This observation holds particularly for curricula that purport to offer a concentration in international relations, international studies, or some similar variant.

At the graduate level, the decline of international law as primary focus of graduate instruction is even more evident. Professional schools of international affairs often, but not uniformly, offer courses-sometimes several. As suits the vocational thrust of such schools (indicated by the term "affairs"), these courses typically use the casebook method preferred for legal instruction in the United States. Few departments of political science now offer a graduate course in international law because few have faculty competent to teach it. By itself, the absence of competent faculty forms a devastating commentary on how the discipline in 
general views the relevance of international law. Obviously, without some external stimulus to change priorities at the graduate level, the absence is self-perpetuating. The bulk of instructors in the United States who offer such courses are middleaged or older. With no successor cohort in training, we can truly speak of disciplinary death in liberal arts curricula with the retirement of this generation of teachers.

Advanced courses in IR (upper division undergraduate as well as graduate courses) focus on matters of theory. Indeed, without a theoretical core, IR as a field of study has no disciplinary credibility. Theoretical claims and concerns define the agenda for graduate instruction. A priori, there is absolutely nothing in the quest for IR theory that necessarily excludes international law as an important component of the enterprise. Much of the blame for the perceived lack of relevance lies with scholars of international law who failed to respond to the challenges posed by the peculiar circumstances post-1945 attending the emergence of IR as a self-conscious disciplinary undertaking. The thrust of disciplinary theory development in IR relegated interest in international law to vocationally minded law professors, idealists, and foreign scholars hopelessly focused on formal institutional models, all of which suppose some conception of "law" (and by extension, obedience to law) as a central concern of both analysts and statesmen.

A recent resurgence of interest in normative theory among a number of American teachers and scholars concerned with the development of systematic theory in IR has included a renewed interest in the relevance of international law to a more complete understanding of how the world works. In particular, the focus on factors and conditions that promote cooperation in anarchy has led IR scholars to consider once again the problems of rule generation, rule patterns, rule maintenance, and rule decay. For example, much of the work on "regimes" has consciously avoided the traditional language of international law while borrowing extensively from its conceptual base.

Given the interest in international law among "leading scholars," there are undoubtedly others who could be persuaded of its relevance as an important area of study. We do not contend that international law should form a central focus, but we do believe that it forms a persistent descant to familiar themes, and one that deserves more serious attention in terms of development given recent trends. What is needed is further thought on how international law can be introduced into the typical

\section{$A$ recent resurgence of}

\section{interest in normative}

\section{theory among a number}

of American teachers and

scholars concerned with

the development of

systematic theory in IR

has included a renewed

interest in the relevance

of international law

to a more complete

understanding of how the

world works.

graduate course in international relations.

A serious treatment requires that we give considerable thought to a thorough integration, and not take the easy way by doing what instructors customarily do in undergraduate IR classes. In the typical undergraduate course, the instructor devotes a class period or two to international law, addressing questions of scope, sources, and efficacy so quickly and superficially that students see little connection with the rest of the course. At best, students have a still picture of international law as something totally apart from the rest of IR's concerns-an area so technical and inaccessible that one has to be a lawyer to understand it. At worst, students find support for their lurking suspicions that international law truly is an irrelevant fiction.
Integration means that instructors must make an effort to show how international law fits in with, and adds to, the conceptual foci that most graduate courses in international relations cover. The following suggestions certainly do not exhaust the possibilities, but reflect our experience in teaching graduate courses covering those theoretical and substantive concerns now garnering the lion's share of attention in the field. In passing, we must also note that none of our suggestions are couched in the traditional language of international law, which after all is the language of law and not social science.

\section{A Perspective and Some Definitions}

To begin, to speak of international law unproblematically as law constitutes a serious discursive error. Students will want to dispute the tired question: Is international law truly law? As noted above, any convincing answer would take the discussion far into the realm of jurisprudence which almost by necessity removes the issues far from the world of IR. By extension, pragmatism suggests that the willingness of instructors to prepare themselves to deal with issues so remote from what they define as their central concerns will rapidly fade as well. A less than convincing answer to this question for both students and instructors will merely reinforce the propensity to dismiss international law as ineffective and irrelevant.

To build on current work we suggest that instead of tackling the "is international law really law" question head on, the focus should be on rules and patterns of rules with a notation, almost an aside, that rules of considerable formality are generally characterized as "legal." In point of fact, instructors should eschew deep forays into modern legal theory because the narrow conception of the nature and role of rules found there will stifle rather than encourage thought about the issues (Onuf 1989, 66). 
Some instructors (as do many introductory texts) may prefer to speak of "norms" rather than "rules." For many purposes, the terms may reasonably be used interchangeably. Nevertheless, we prefer "rules" because the term conveys more specifically an important attribute of all law: prescriptive or "normative" guidance must take the form of linguistic statements subject to affirmation, violation, repudiation, alteration, extension, replacement, collation, or various other logical operations. These statements form the working materials for construction of social arrangements (institutions), and they offer people involved in those arrangements intelligible, relatively unambiguous choices for their conduct.

In contrast, "norms" suggest something ineffably imprecise, inchoate, and culturally dependent. One may speak of a "rule of decision," but it makes little sense to speak of a "norm of decision," although writers do talk about norms that "condition" decisions or the decision context. In either case, the connections between norms and action seem diffuse, ill defined, and easily ignored or dismissed.

Rules aid our quest in another way. The use of "rule" analogies and metaphors is ingrained in our methods of discourse so that most students will respond intuitively to their use. The same holds true of "game" analogies and metaphors. Virtually everybody in every conceivable context talks about the "rules of the road" or the "rules of the game." Practically everyone plays games or follows them with sufficient care to understand that games are what they are because of their rules: different rules, different game. Indeed, in another context, James N. Rosenau (1967) has effectively used the game analogy to dramatize the different research strategies IR scholars may use.

Game metaphors have another vital use because the nature, function, and types of rules may be more easily introduced than through a direct examination of the international context. Instructors can easily illustrate that rules have different levels of specificity, function, and formality and that unwritten rules (customary usages) may play a great role in the actual course of play. For example, the rule that a ball on, or inside, a boundary line constitutes a good shot defines an essential rule of the game of tennis. The rule that when a player cannot make a definite call on an opponent's shot, he or she must presume the ball good (i.e., the opponent gets the benefit of any doubt) forms an important (and often violated!) unwritten contextual rule of decision.

"Opponent gets benefit" is more than good manners, but less than an

.. we suggest that
instead of tackling the "is
international law really
law" question head on,
the focus should be on
rules and patterns of rules
with a notation, almost
an aside, that rules of
considerable formality are
generally characterized as
"legal."

essential rule. Individuals can compete without observing the rule, but nonobservance can materially affect the course of play, the "atmosphere" of play and perhaps the status for future invitations to play for individuals who do not observe the rule. Every day individuals with different levels of skill and understanding of the rules compete with each other and make authoritative judgments using the rules as they comprehend them. Disputes may arise, but these too are settled as a matter of course by the participants, not through recourse to third party judgment.

It does not require a great leap of understanding to move from consciously devised games to social arrangements. Students perfectly well understand that the "game of nations" has its own rules. Furthermore they can easily use that understanding to defeat the presumption that the subject matter of IR forms an exception-so exceptional that the extreme characterization of anarchy describes the fundamental conditions of the playing field.

On its face the game of nations, as true of any game, has rules unique to its play. To begin, formal rules define the constituent conditions that determine player eligibility and the process through which players enter or leave the game. Other rules come from formal agreement among the players, binding those who give their consent (treaties). Still others flow from tacit agreement or patterns of strategic interaction that constrain alternative courses of action, and in doing so, foster expectations about those options remaining. Many spring from functional necessities such as the need for communication and for minimizing the hassles of ongoing contact ("housekeeping rules'). Nonetheless, despite their origins, to quote some folk wisdom relevant to our general approach and argument, "rules (still) are rules" and identifiable as such. In the following analysis we shall focus upon two fundamental roles rules play in regulating interaction between and among "players": the structuring of choice and the ascription of responsibility.

\section{Folkrules and Behavior}

The process whereby general usage generates identifiable rules is dynamic and part of every possible social setting. Some rules are continuously reinvented (e.g., envoys deserve special status and privilege); others are diffused from game to game (e.g., participants must survive). Consequently, it would be surprising if we did not find many of the informal rules of international relations, particularly those which structure choice or ascribe responsibility, familiar as "folkrules" because we acknowledge or intuitively understand their applicability in many other settings, or, if you please, commonly played games. Folkrules come from the distillation of human experience: "they display a sound practical sense which even the law itself has not always been able to put into better words. . "' (Taylor, 88). Many folkrules have a universal 
quality in that they express "rules of thumb" people use in making choices in many different cultures and settings. Students will recognize these even though they will not necessarily have associated the relevant judgments with international politics.

To begin, let us take the folkrule, "first things first." Hardly a tautology, in practice the rule eases choice among many competing alternatives. It is indispensable to agenda setting and helps account for the primacy assigned to questions of security in IR. Indeed, recent efforts to reconceptualize security to include such matters as environmental degradation and economic development demonstrate an intuitive understanding and acceptance of the power of this one rule. Similarly, the folkrule, "players take turns," is as relevant to diplomacy and strategic relations as it is to personal conversational practices. This rule underlies more formal rules acknowledged as international law such as the rules governing the conduct of reprisals. As a final example, the folkrule, "every ship has a captain," establishes univocality for players. Because of the longstanding association between ship and state, this rule is but an informal rendition of the complex of international legal rules constituting sovereignty, agency, and responsibility as decisive features of the games nations play.

To suggest that players participate in games by following rules they all know supposes that all participants are competent to play and responsible for the consequences of playing. In other words, this position presumes that actors are autonomous, goal-oriented, and rational beings. Yet graduate IR courses normally include a body of literature which suggests that the relevant players frequently make irrational choices/ decisions, and not just randomly so.

If players are rational by definition, but irrational in practice, then it would seem that they make systematic errors in the way they see their situations. While current convention characterizes these errors as "misperceptions," we may call them just as well the untoward consequences of having resorted to misleading folkrules. For example, the folkrule, "first things first," would seem to account for the apparently irrational tendency people have, when they consider "everything else to be equal," of taking the first in a set of alternatives. It may, indeed, fundamentally conflict with "players take turns." To give another example, the folkrule, "every ship has a captain," supports the perception that one's adversary is unambiguously competent (and free) to act decisively, while one's own situation, seen close at hand, is obviously not that simple. The frequency of this misperception, or attribution error, promotes another folkrule, namely that "people always get away with things" (but you don't, so don't even try).

Before rejecting these observations, reflect upon what this line of argument suggests about facts of everyday life we often take for granted. Consider that each of the foregoing examples has at its core a question of choice. Questions of choice often, either overtly or by implication, also often raise questions of who has the authority/responsibility to make the choice. One way of unraveling the complex situations in which rational people find themselves is to focus on the importance of rules in making choices. After all, most choices are alternatives either posed by a ruledoes one follow the rule or not? or between rules-does one follow this one or that one?

\section{Realism, Regimes, Rules, and Relevant Relationships}

For the past several years serious students of IR have debated questions that center on the origin and maintenance of cooperative efforts among states. "Regime," defined as a set of "implicit or explicit principles, norms, rules and decisionmaking procedures around which actors' expectations converge for a given area of international relations," has emerged as the concept of choice in this endeavor (Krasner 1982, 186). Notice that this definition indicates that rules and the like define the game (regime). By any reasonable construction the term "explicit" as used by Krasner (or "formal" in some other usages) is unambiguously an interchangeable synonym for "legal."

Given our earlier discussion, the studied indifference to law should not surprise anyone; but, given the focus on international economic arrangements among writers who have adopted "regime" as an explanatory framework, the omission is certainly unwarranted. The World Bank (IBRD), IMF, the GATT and other institutional arrangements indisputably rest upon legal foundations, whatever the analyst's preferred explanation for their genesis and operation. Even the new "institutionalists" (see Yarbrough and Yarbrough 1990 as example) prefer to ignore the obvious by confining their focus to process (organization theory). In defense of this deliberate oversight, Keohane argues:

What international regimes can accomplish depends not merely on their legal authority, but on the patterns of informal negotiation that develop within them. Rules can be important as symbols that legitimize cooperation or as guidelines for it. But cooperation, which involves mutual adjustment of the policies of independent actors, is not enforced by hierarchical authority (Keohane 1984, 237).

We can accept this position as the thrust of our previous analysis clearly illustrates. What we cannot accept is the consequent inference, that in such institutions, whatever their origin, absent the threats associated with hierarchy, the "symbols or guidelines" necessarily play secondary or insignificant roles when governments choose to dispute particular policy choices flowing from the "process." At the very least, within these institutional arrangements, the rules still remain part of relevant considerations because they "reduce bargaining costs by providing templates for wholesale advance coordination"' (Kratochwill 1984, 70). Consistent with our earlier commentary, the rules also structure the calculus of actual choice(s) in terms of opportunity costs, benefits, and side payments. Governments seldom, if ever, bargain in a vacuum, even on issues that do not directly concern formal institutions.

Keohane, himself, acknowledges the general thrust of our position, 
arguing that regime rules have the advantage of constraining the actions of others. In addition, he notes that, "The choice that governments actually face is not whether to adhere to regimes at the expense of maximizing utility through continuous calculation, but rather on what rules of thumb to apply" (Keohane 1984, 115).

The refusal to acknowledge any impact of law beyond the narrow, untenable association with formal institutional arrangements permeates the influential work of Kenneth Waltz as well. Waltz argues that the system of international relations is structurally similar to a market, but only up to a point:

Market economies are hedged about in ways that challenge energies constructively. One may think of pure food and drug standards, antitrust laws, securities and exchange regulations, laws against shooting a competitor, and rules forbidding false claims in advertising. International politics is more nearly a realm in which anything goes (Waltz 1979, 91).

While attractive on its face as a concise statement of the harsh Realist picture of IR that many students find intuitively appealing, Waltz's conclusion does not capture the complexity of contemporary state relationships, nor on reflection does it embody the experience of the greatest part of the industrial age. The most obvious problem with Waltz comes from his willful disregard of the rules, formal and otherwise, that impinge on state action. These range from fundamental rules inhibiting the absorption of lesser states by larger ones as the international political equivalent of trust formation to extensive institutional support for international monetary and financial coordination, to laws protecting diplomats and state visitors to nutritional standards sponsored by the Food and Agricultural Organization (FAO). True, rules against false advertising have no direct international legal equivalent, but then, what is the need?

Implicitly Waltz suggests that the difference between the laws he enumerated and comparable international rules is the greater efficacy of the former because of the perceived lack of enforcement mecha- nisms at the international level. Merely reading the newspapers gives sufficient evidence that Waltz's position has serious defects because he overestimates the efficacy and automaticity of the domestic legal order, while underestimating the extent of rule based behavior at the international level. Pure food and drug standards hardly spare us contaminated foodstuffs; oligopoly is a dominant feature of many contemporary industrial sectors; abuse of security and exchange regulations seems to occur on a regular basis; and, drug dealers routinely shoot each other. We, or any observer of modern life, could extend this list almost indefinitely. For examples, we need only point out the general lack of observance of speed limits, the relatively high probability that burglars will escape apprehension, or the comment by an insurance executive in Los Angeles that "to own a nice car is to have it stolen."

Less obvious about Waltz's position, but no less important for our purposes, is his disregard of the remarkable number of informal rules that structure and constrain markets and alleged anarchies alike. Let us return to his example of false advertising. In this case, we find a folkrule that provides a context for the formal rule proscribing false advertising -the well-known injunction, "buyer beware." Clearly the folkrule affords insufficient protection against unscrupulous, well-financed advertisers. On the other hand, as we pointed out above, the adoption of some specific formal rule, or law, hardly eliminates all avenues for abuse. Nor does the adoption of the formal rule mean the folkrule has been rescinded or replaced: buyers must still be wary. Instead we treat the folkrule and the formal rule as complementary. Taken together with other related rules, they constitute a regime.

Indeed, the competing paradigms discussed by Keohane and Waltz can be represented as bundles of folkrules which embody the principal calculus of utility associated with each. Despite our previous commentary, we will for the moment accept Waltz's assertion that because of security concerns IR is an arena in which "anything goes" as a starting point. "One's home is one's castle," "might makes right" ("it is better to be feared than loved," "it is better to be safe than sorry"), "get while the getting's good" and "get what the traffic will bear' all form essential operating rules of thumb for statesmen who wish to succeed in light of the harsh realities described by "anything goes."

Finally, "a bird in the hand is worth two in the bush"' (the moral of Rousseau's parable of the stag hunt-i.e., "a hare in the hand. . .") expresses the classic tension between the narrowly defined rational selfinterested calculus of Waltz's world and the "enlightened" rational selfinterested calculus necessary to establish and maintain cooperative efforts. As such it captures the essence of the short-range visions that drive the security dilemma and its attendant phenomena and hence the calculus that paradigms based upon cooperation must address.

In fact, the realities of practice challenge and often modify the rather harsh rules of thumb embodied in the pure Realist paradigm, particularly in the post World War II relationship among the superpowers. If, as Waltz suggests, the controlling folkrule is "anything goes," then its logical corollary would be "might makes right"'; but as Morgenthau observes, rules of thumb based upon prudence modify the application to real situations. "What's mine is mine, what's yours is yours" has long supported the reciprocal acceptance of spheres of influence whatever superpower leaders may have said about such matters. Might makes right, but only in what we both acknowledge as yours (or mine); or as the folkrule, "it takes two to tango" intimates, the relationship is jointly and consciously maintained (see Larson 1989, 7). Outside of acknowledged spheres of influence, "one's home is one's castle" as a rule of considerable formality severely limits the scope and domain of might makes right even though the extent of castles and sometimes family ownership is often at issue.

In fact the rules of reciprocity/ proportionality, whether expressed as Vattel's Golden Rule of Sovereigns, "one cannot complain when others treat you as you treat them," or the 
more earthy "what's sauce for the goose is sauce for the gander" ("as you sow, so shall you reap") are indispensable implements for analyzing modern international politics. Not only do they condition the parameters of the logic of justification, but in large part they also form the fundamental framework for examining contemporary state interaction, if not the bridge between competing paradigms.

From the rules of reciprocity/ proportionality it is but a small step to the functional calculus of utility which constitutes the foundation of the regime/complex interdependence literature. The folk rules- "two heads are better than one," "'all covet, all lose," "you must give some to get some," and "there is safety in numbers",-express the essence of this perspective based upon enlightened rational selfinterest. From this perspective, it then becomes easy to point out that liberal international trade theory and the positivist school of international law share common 18th and 19th century roots. ${ }^{1}$ Using our approach yields a complementary explanation for Keohane's observation that "after hegemony, governments persist in trying to build viable international regimes"' $(1984,240)$. It explicitly forces attention to "the value of institutions and the costs of flexibility."

\section{Conclusion}

As we noted at the beginning, we regard this discussion as suggestive, not exhaustive. Our main point is that modern IR theorists and practitioners have generally lost sight of the multiple functions that rules (and norms) play in interactions among states. Regardless of the reasons why, the oversight has important implications for the future of IR as a discipline. The disappearance of international law from graduate curricula means simply the virtual disappearance of international law as a viable subfield in an era where the dynamics of international politics seem to have generated institutions, formal and informal, at a geometric rate. It has to be one of the more interesting ironies in the long history of the academy, that a discipline has chosen to abandon an important substantive focus at exactly the time when the subfield's most significant objects of study have expanded and flourished. As a subfield, international law has much to contribute to an understanding of the contemporary world and to the past. Indeed, IR theory cannot make its future without finding its past, a past of discursive richness and variety, a past shared with international law, but acknowledged alone by international law.

\section{Notes}

*Students of international law will recognize the allusion to Roger Fisher's noted essay, "Bringing Law to Bear on Governments." Our essay integrates and extends remarks each of us made at a Roundtable on Teaching International Law, 36th Annual Convention, International Studies Association, Washington, D.C. (March 1990).

1. As does modern strategic theory. For example see Schelling (1966).

\section{References}

Fisher, Roger. 1961. "Bringing Law to Bear on Governments." Harvard Law Review
74: $1130-40$.

Keohane, Robert O. 1984. After Hegemony. Princeton: Princeton University Press.

Krasner, Stephen D. 1982. "Structural Causes and Regime Consequences: Regimes as Intervening Variables." International Organization 36: 185-205.

Kratochwil, Friedrich, 1984. "The Force of Prescription." International Organization 38: 685-708.

Larson, Deborah. 1989. "OOrder under Anarchy: The Emergence of Convention in U.S.-Soviet Relations," paper prepared for the 1989 Annual Meeting of the American Political Science Association, Atlanta.

Onuf, Nicholas. 1989. A World of Our Making. Columbia, SC: University of South Carolina Press.

Rosenau, James N. 1967. "Games International Relations Scholars Play." Journal of International Affairs 21: 293-303.

Schelling, Thomas. 1966. Arms and Influence. New Haven, CT: Yale University Press.

Taulbee, James Larry. 1988. “Images of International Law: What Do Students Learn from International Relations Textbooks?" Teaching Political Science 15: 71-79.

Taylor, Archer. 1931. The Proverb. Cambridge: Harvard University Press.

Waltz, Kenneth N. 1979. Theory of International Politics. Reading, MA: AddisonWesley.

Yarbrough, Beth V., and Robert M. Yarbrough. 1990. "International Institutions and the New Economics of Organizations." International Organization 44: 235-59.

\section{About the Authors}

Nicholas Onuf is professor, School of International Service, American University. $\mathrm{He}$ is currently writing on republicanism in international thought.

James Larry Taulbee is associate professor of political science at Emory University. His recent work has focused upon mercenary soldiers and modern conflict, and questions of extradition/political asylum. 